UDK 528.935

\title{
LIETUVOS EŽERŲ VIETOS IR VARDŲ NEATITIKIMAI KADASTRO DOKUMENTUOSE
}

\author{
Romualdas Girkus ${ }^{1}$, Viktoras Lukoševičius ${ }^{2}$ \\ ${ }^{1}$ Aerogeodezijos institutas, Pramonès pr. 13, LT-51382 Kaunas, Lietuva, \\ el.paštas: info@agi.lt \\ ${ }^{2}$ Kauno technologijos universitetas, Panevėžio institutas, Klaipédos g. 1, LT-35209 Panevéžys, Lietuva, \\ el.paštas:vikluk@midi.ppf.ktu.lt
}

lteikta 200701 22, priimta 20070330

\begin{abstract}
Santrauka. 2003 m. parengtas oficialus Lietuvos ežerų klasifikatorius, ị kuri ịtraukta ežerai nuo 0,5 ha ploto. 1998$2001 \mathrm{~m}$. išleisti Aerogeodezijos institute sudaryti oficialūs Lietuvos Respublikos M 1:50 000 topografiniai žemėlapiai, kuriuose kartografuoti tokio ploto ežerai. Straipsnyje Žeimenos baseino ežerų pavyzdžiu aptariama ežerų vietos ir vardų neatitikimai šiuose leidiniuose. Analizuojami kalbininkų leidiniai, kuriais remtasi ịvardijant ežerus, ankstesnių metų ežerų kadastriniai dokumentai.

Lietuvos kartografinèje medžiagoje ir kituose informaciniuose šaltiniuose vandenvardžiai turètų būti teikiami vienodi ir tik norminiai. Straipsnyje nurodyti ir oficialiuose leidiniuose aptinkami ežerų vietos bei vardų neatitikimai klaidina vartotojus, kelia sunkumų nustatant objektų tapatybę ar esant būtinumui rasti juos vietovèje. Esama padètis taisytina. Svarbu nekartoti klaidų rengiant skaitmeninę Lietuvos vietovardžių duomenų bazę.
\end{abstract}

Reikšminiai žodžiai: klasifikatorius, topografiniai žemėlapiai, upès baseinas.

\section{Ivadas}

Lietuvoje suskaičiuota 2850 didesnių kaip 0,5 ha ežerų ir 3150 mažesnių kaip 0,5 ha natūralios kilmès ežeriukų [1]. 1964 m. Respublikinio vandens ūkio projektavimo instituto (RVŪPI) sudarytame 0,5 ha ploto ir didesnių Lietuvos ežeru saraše su morfometriniais duomenimis yra 2883 ežerai [2]. Norint įtraukti i apskaitą nedidelio ploto ežerus, reikalinga tinkamo mastelio kartografinė vietovės išraiška. Pavyzdžiui, 1:100 000 mastelio žemèlapyje 0,5 ha ploto ežeriuko matmenys yra 0,7 mm. Lietuviška prieškarinè M 1:100 000 topografija apémé apie 2/3 Lietuvos teritorijos, o M 1:25000 - tik apie devintadali centrinès Lietuvos [3]. Pokariu leistuose M 1:10 000-1:100 $000 \quad$ sovietiniuose žemėlapiuose dažniausiai įvardyti tik didieji ežerai, ir tai iškraipytais vardais, rusiškais rašmenimis. Todèl sudarant ežeru kadastrą labai aktualus buvo naujas Lietuvos topografinis kartografavimas M 1:50 000 (baigtas 2000 m. pradžioje). Kaip tik tuo metu Lietuvos aplinkos ministerijos paskirta institucija parengè Lietuvos Respublikos ežeru klasifikatoriu (2003) [4], i kuri itraukti 0,5 ha ploto ir didesni ežerai.

Darbo tikslas - išanalizuoti Lietuvos ežeru lokalizacijos ir vardų neatitikimus kadastriniuose dokumentuose.

\section{Kalbininkų veikalai apie ežerų vardus}

Lietuvos Respublikos upių, ežerų ir tvenkinių valstybės kadastro rengimo nuostatose, įvardijant upes ir ežerus, pirmenybè teikiama Lietuvos TSR upiu ir ežeru vardynui [5] ir A. Vanago Lietuviu hidronimy etimologiniam žodynui [6]. Kalbininkai apie lietuvių hidronimus naujesnių veikalų neparengè, išskyrus Vietovardžiu žodyna [7], kurio pratarmèje rašoma apie i žodyną įdètus 10 ha ir didesnių ežerų vardus. Iš minimų veikalų tik Lietuvos TSR upiu ir ežeru vardyne (1963) pateikiamas konkretesnis ežerų aprašymas, iš kurio įmanoma identifikuoti ežerus žemėlapyje. Lietuviu hidronimu etimologiniame žodyne pateikiamos tik žinomesnių gyvenviečių, esančiu aplink ežera, nuorodos, o Vietovardžiu žodyne - vien tik administracinis rajonas. Turint tokią informaciją apie ežerų vieta, ežeringoje vietovèje įmanoma identifikuoti tik didžiuosius ežerus.

1964 m. ežerų sąrašui parengti surinkti vardai M 1:100000 trapecijomis buvo pateikti aprobuoti Lietuvių kalbos ir literatūros institutui. Tai paskatino institutą išleisti Vardynq. Jame ežero vieta dažniausiai pagrịsta arčiausiai ežero esančiu kaimu ar vienkiemiu. Kai ežeras yra atokiau nuo kitų panašaus dydžio ežeru, pagal šią aprašomają informaciją ežerą i̇manoma identifikuoti. Šia galimybe ir naudotasi įvardijant ežerus M 1:50000 topografiniuose žemėlapiuose ir teikiant kalbininkams peržiūrèti vardus prieš išleidžiant žemèlapi.

\section{Pagrindiniai ežerų kadastriniai dokumentai}

Aptarę išleistus žemèlapius ir leidinius ežerų vardams identifikuoti ir įvardyti, panagrinèsime parengtus esminius ežerų kadastrinius dokumentus, t. y. 1964 m. RVŪPI sudarytą ežeru sąrašą ir 2003 m. ežeru klasifikatorių. Pirmajame nurodyti ežerų vardai, kodifikavimo ir identifikavimo numeriai, ežero geografine padètis pagal upių ir ežeru gretimybę, ežero plotas, jo matmenys ir kt. Neįvardyti ežerai turi kodą ir identifikavimo numeri, kuris buvo nustatomas remiantis 1942 m. koordinačiu sistemos M 1:100 000 topografiniu 
žemėlapiu, pagal salygini žemėlapio numerị ir žemėlapyje pateiktų baseinų numeravimo eilès skaitmenị. Pavyzdžiui, ežero identifikavimo numerio išraiška: 43102. Skaičius iki brūkšnelio rodo salygini žemèlapio numeri, o po brūkšnelio - ežero numeri žemėlapyje. 0,51,0 ha ploto ežerai dažnai būdavo pavadinami greta esančių vienkiemių vardais. Kadangi topografiniai žemėlapiai, kuriuose fiksuota ežerai, tuo laikotarpiu buvo isslaptinti, ežerų sąrašo prieduose teko sudaryti ežerų su identifikavimo numeriais ir vardais bei jų upių baseinais schemas, ibrèžiant žemėlapių kraštines. Šių ežeru inventorizavimo duomenų nebuvo, leidykla neįdejjo, tad jie liko tik žinybiniai. Didelių matmenų schemos buvo nepatogios naudoti, todèl ežeru identifikavimo numerius imta kelti i M 1:100000 žemès naudojimo schemas administraciniais rajonais. Maži, $0,5-1,0$ ha ploto, ežeriukai šiose schemose buvo sunkiai nustatomi, tad neretai praleidžiami. Remiantis Lietuvos ežeru sqrašu (1964) buvo parengtas Lietuvos Respublikos ežeru klasifikatorius (2003), ji aptarsime Žeimenos baseino pavyzdžiu.

\section{4. Žeimenos baseino ežerų kadastriniai dokumentai}

Žeimenos baseinas išsiskiria mažų ežerèlių gausa. Tai viena iš ežeringiausių Lietuvos vietovių. Ši teritorija ikikariniu laikotarpiu nebuvo kartografuota, didesne jos dalis buvo atsidūrusi už demarkacinès linijos, t. y. okupuota Lenkijos. Ši teritorija tapo išskirtine ir Lietuvos MA Fizikinių-techninių problemų instituto specialistams, kurie renge leidinius apie Lietuvos upes ir atskirą - apie Pietryčių Lietuvos ežerus [8]. Šio leidinio prieduose pateikti Pietryčių Lietuvos upių baseinų ežerų sąrašai. Taigi galime palyginti 1964, 1976 ir 2003 m. kadastrinius ežeru duomenis.

1964 m. Žeimenos baseino ežeru schemą sudaro aštuoni M 1:100000 žemèlapio lapai (ežerú identifikavimo numeriai iki brūkšnelio yra skirtingi skaičiai). Numeruojant kai kurie ežerai buvo praleisti, todèl nepernumeruojant jiems suteikti neatitinkantys gretimų ežerų numeriai. Tai pasakytina apie Kuprinị (43242), Gavaiti (44-37), Paplovini (32-216), Dumblị (4458), Kogili (31-144) ir bevardi (31-116) ežerus.

Iš sąraše esančiu 527 ežeru 60 yra neịvardyti, juos skiria tik identifikavimo numeris. Ežeru varduose pasitaiko spaudos klaidų (iš dalies perkeltos i $2003 \mathrm{~m}$. sąrašą).

1976 m. ežeru sąrašuose nurodyti ežeru plotai, geografinè upių gretimybė ir kt. Žeimenos baseine apskaičiuota 549 ežerai, 90 iš jų neivvardyti. Lyginant su 1964 m. sąrašu, matyti, kad ežeru skaičius padidejo 22. Daugelis iš jų - neịvardyti maži ežerèliai, išskyrus papildomai šiam baseinui priskirtus Minkeliu ež. (51-7), Verdingi (51-6), Kazimieravo (31-106) ir Zabieliškių ež. (Baltarusijos teritorija). $1976 \mathrm{~m}$. ežeru sąrašuose identifikavimo numeriai pagal $1964 \mathrm{~m}$. numeravimą nenurodyti. Ežeru sąraše, palyginti su 1964 m. sąrašu, įvardyta mažiau ežerų. Ežerų vardai iš esmès tokie pat kaip 1964 m. sąraše, tačiau yra spaudos klaidų: Kueika (Nr. 282, turi būti Kuceika), Ešeras (Nr. 375, turi būti Ežeras), Pakanis (Nr. 383, turi būti Pakapis). Leidinyje esanti Žeimenos hidrografinè schema apima tik didžiuosius ežerus, bet ir jie ne visi îvardyti. Kadangi daugumos ežeru geografinè padètis sąraše apibūdinta tik upès baseino pavadinimu, negalima identifikuoti bevardžio ežero žemėlapyje.

2003 m. ežerų klasifikatoriuje išliko 1964 m. ežeru identifikavimo numeriai, jame Žeimenos baseine suskaičiuota 530 ežerų. Palyginti su 1964 m., ežerų padaugèjo, nes ịvardytas Minkelių ež. (51-7), Minadžio (43-149) ir Vašuoko ež. (identifikavimo numeris nesuteiktas), o 1976 m. teiktas ežerų skaičius nepriimtas, nors ežeru plotai tie patys. Iš $1964 \mathrm{~m}$. neįvardytų 60 ežerų sąraše i̇ašyti 8: Krakežeris (31-147), Krakežeris (31148), Velniavardžio ež. (32-85), Dumblis (32-88), Ešerinis (32-95), Juodapurvis (43-177), Ežeras (43-200), Karosininkas (43-265). Ežeru geografinè charakteristika teikta naujai, nurodant tiesioginio ir senesniojo vandentakio vardus, ir papildyta administraciniu rajonu. Apmaudu, kad kartais klaidina ežero administracine priklausomybè. Pavyzdžiui, Baltelis (52-5), Gaigalis (5210) ir Gaigaliukas (52-6) yra ne Švenčionių, o Vilniaus rajone; Karnelis (42-115) - ne Molètu, o Vilniaus rajone; Tuolas (44-28) - ne Švenčionių, o Ignalinos rajone; Dumblis (31-171) - ne Utenos, o Moletu rajone; Žiezdrelis (43-48) - ne Švenčionių, o Utenos rajone.

\section{2003 m. ežerų klasifikatoriaus ir 1998-2001 m. M 1:50 000 topografinių žemėlapių skirtumai}

Žeimenos baseino M 1:50000 žemèlapiai Aerogeodezijos instituto parengti 1998-2001 m.. Jie sudaryti WGS-84 koordinačiu sistemoje, bet pagal rėmelius yra tokie pat kaip žemėlapiai, parengti $1942 \mathrm{~m}$. koordinačių sistemoje (juose ežerai sunumeruoti). M 1:50 000 yra kartografuoti visi 0,5 ha ploto ir didesni ežerai, nustatant jų vardus remtasi Vardynu (1963). Tai leidžia klasifikatoriuje pateiktą informaciją apie ežerus paanalizuoti. Sąrašinis Geronių ežeras (52-18) „išnyko“ kartografuotoje Garoniu pelkèje (1 pav.).

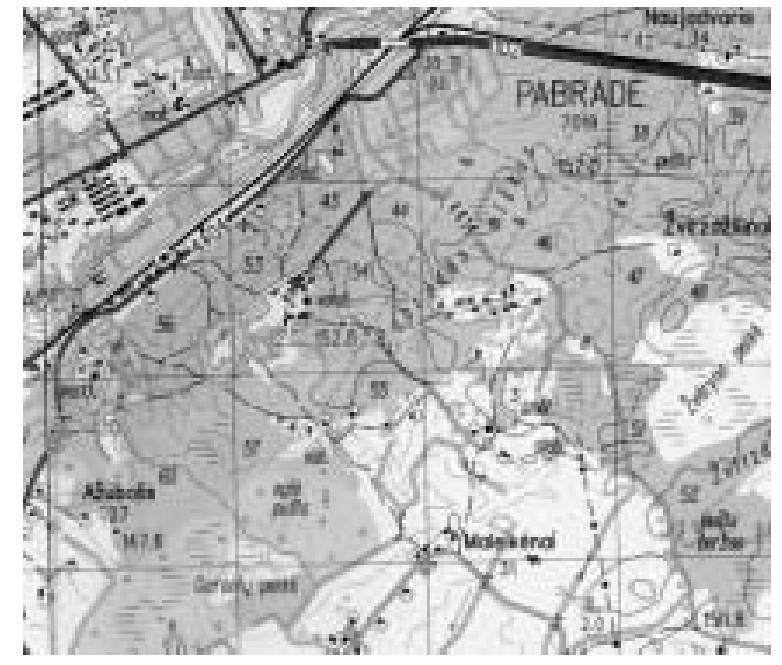

1 pav. Lietuvos M 1:50000 topografinio žemėlapio PABRADE, N-35-40-AB, 2001 m. fragmentas. Garonių pelkès aplinka

Fig 1. Fragment of Lithuanian topographic map M 1:50 000 PABRADE N-35-40-AB, 2001, environment of Garoniai bog 
Gerokai skiriasi ežerų vardai. Klasifikatoriuje Gelednia (52-32) iš tikruju yra gretimame žemèlapyje, o tuo numeriu identifikuojamas ežeras Skeimis; Žiezdrelis turètų būti ịvardytas Gelednia (2 ir 3 pav.).

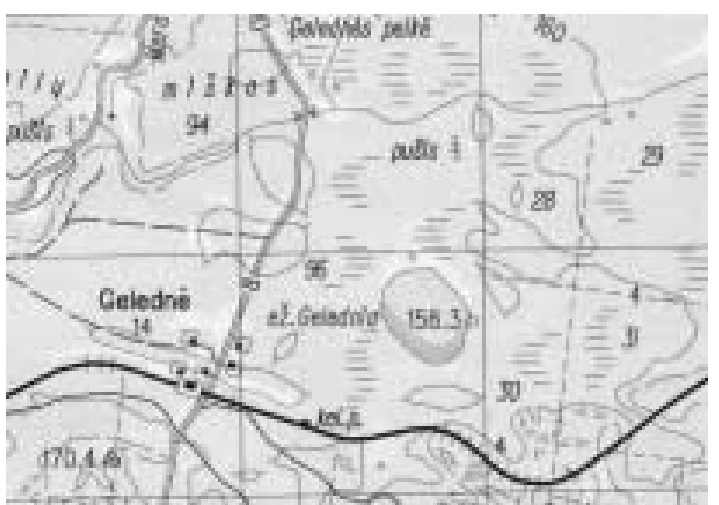

2 pav. Lietuvos M 1:50000 topografinio žemèlapio GELEDNE, N-35-41-AB, $2001 \mathrm{~m}$. fragmentas - Gelednios ežero aplinka

Fig 2. Fragment of Lithuanian topographic map M 1:50 000 GELEDNĖ N-35-41-AB, 2001, environment of Gelednè lake

Ši ežeru painiava buvo ir 1964 m. ežerų sąraše. Iš esmès, remiantis klasifikatoriumi, turètu būti: Baltis (3284) - Baltys, Baluošas (43-278) - Baluošai, Buivydas (43-169) - Telys, Buvainèlis (32-67) - Byvainèlis, Dumblys (32-88) - Dumblis, Gervèlis (32- 69,70,71) Gervètis, Gilutis (43-108) - Bliūdinèliai, Juodenis (43111) - Aukšlinis, Juskutis (32-80) - Joskutis, Kampuolis (43-210) - Kampuotis, Karotys (43-186) - Kerotys, Krakinis (43-230) - Krakinys, Kuojinis (31-153) Žvingys, Labažas (43-108) - Labažis, Miškinis (32-68) Žiegžmaris, Minadis (43-149) - Miruolis, Montviliškio ež. (31-170) - Ešerinis, Paglūštis (43-324) - Paglūšties ež., Paledinis (32-105) - Pelèdinis, Paštikis (32-124) Varlys, Savičiaus ež. (44-24) - Krakinis, Sudètèlis (43243) - Sudotèlis, Tamsus (43-305) - Juodasai, Vienvalkšnys (43-145) - Šiekštelis.

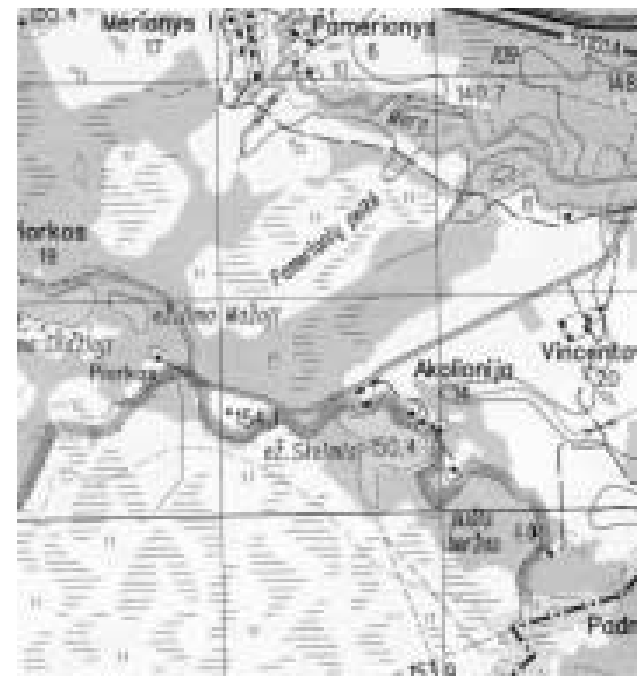

3 pav. Lietuvos M 1:50000 topografinio žemèlapio PABRADE், N-35-40-AB, 2001 m. fragmentas - Skeimio ežero aplinka

Fig 3. Fragment of Lithuanian topographic map M 1:50 000 PABRADE N-35-40-AB, 2001, environment of Skeimis lake
Naujausiame Vietovardžiu žodyne (2002 m.) [6] Baltelis (32-65) ivvardytas Baltelè, Žiežulinis (43-29) Žiežulnis, Purvinas (43-310) - Purvynas, Rèdzė (43317) - Rèdžia. Kitus klasifikatoriuje pateiktus ežerų vardus, nesunormintus kalbininkų, palyginę su $1964 \mathrm{~m}$. ežerų vardų schema, galime teigti, kad Balutis (43-258) ivvardytas Balkutis, Girvežeris (43-155) - Gervežeris, Gilulis (52-28) - Gilutis, Lakajas (43-178) - Lakaja, Lakajos (43-227) - Lakajas, Leikštėnu (43-311) Leikštekių ež., Leikštinis (43-291) - Leikštèkis, Oklelis (52-14) - Aklelis, Pailgis (52-27) - Pailgiu ež., Pašliaužukas (43-314) - Pašlaužukas. Iš šių ežerų Gervežeris, Leikštekių ež., Leikštėkis bei Pailgiu ež. taip pat ịvardyti ir 1976 m. sąraše [9]. Kai kurių ežerų vardai klasifikatoriuje pateikti tarmiškai, pavyzdžiui: Paledinis (32-105), Untinèlis (43-157), Malynè (43-262), Oklelis (52-14), Sravinaitis (32-81).

Topografiniuose žemèlapiuose ivardyti klasifikatoriuje likę bevardžiai ežerai: Daujotiškès ež. (42-95), Akelè (43-79), Varliokas (43-83), Maskoliukai (43-85), Narvinis (43-33), Dumblelis (43-120), Salinis(31-172), Ešerinis (43-216), Liūnelis (43-21), Dèlinis (43-32), Desiškis (43-251), Varliukas (43-21), Obelynès ež. (43-31), Dumblelis (43-35), Pugžlinis (4374), Karosinukas (43-84), Balinis (43-202), Girinių ež. (43-257), Karosininkas (43-264), Migline (43-261), Varnakèlis (43-322), Mūkuškis (43-47) ir Batelis (43-49). Reikia pasakyti, kad ežero vardas išskiria ji iš kitų neịvardytų panašių ežerų gretimybès, ir ežero radimo žemėlapyje galimybė padidèja. Tad ežero vardo nebuvimas yra jo kadastrinès kokybès lygio praradimas. Kartografų surinktus ir su kalbininkais suderintus ežeru vardus tikslinga perkelti ir i ežerų klasifikatorių. Topografiniuose žemėlapiuose pasitaiko mažų ežerèliu, ịvardytų kitaip negu klasifikatoriuje pagristai įteisinti jų vardai: pavyzdžiui, Kamša vietoj Kuceika (43-170), Viarža vietoj Biržuvė (52-3), Bedugnis vietoj Beduonai (52-30). Jie turètų būti įvardijami remiantis pirminiu šaltiniu, t. y. Lietuvos ežeru sqrašu (1964).

\section{Išvados}

1. Respublikinis vandens ūkio projektavimo institutas $1964 \mathrm{~m}$. Lietuvos ežerų inventorizaciją atliko tinkamai, nes 2003 m., praejjus beveik 40 metų, Lietuvos aplinkos ministerijos kuruojamam Lietuvos Respublikos ežeru klasifikatoriui parengti iš esmès naudota šios inventorizacijos medžiaga.

2. Lietuvos MA Fizikinių-techninių energetikos problemu instituto parengtame $1976 \mathrm{~m}$. leidinyje Pietryčiu Lietuvos hidrografija (ežerai) Žeimenos baseino ežeru sąrašas, palyginus su 1964 m. sąrašu, papildytas 21 ežeru (tai dažniausiai maži, anksčiau neịvardyti ežerèliai). Dèl konkretesnių vietos nuorodų stokos jų identifikuoti neįmanoma, todèl tokie ežerèliai neįtraukti i 2003 m. ežerų klasifikatoriu.

3. Aplinkos ministerijos parengtame 2003 m. ežeru klasifikatoriuje ežeru vardai nevisiškai suderinti su 1963 m. Lietuvos upiu ir ežeru vardynu, kuris ežeru kadastro nuostatose nurodytas kaip prioritetinis. 
4. 1998-2001 m. išleistuose M 1:50 000 oficialiuose Lietuvos Respublikos topografiniuose žemèlapiuose pateiktus bevardžius ežerus tikslinga įvardyti ir ežerų klasifikatoriuje.

5. Valstybinio žemėtvarkos instituto ir Lietuvos energetikos instituto specialistams su kalbininku pagalba rengiant skaitmeninę Lietuvos vietovardžių duomenu bazę, rekomenduojama atsižvelgti i oficialių topografinių žemėlapių ir ežerų klasifikatoriaus neatitikimus.

\section{Literatūra}

1. GAILIUŠIS, B. ir kt. Lietuvos upès. Hidrografija ir nuotékis. Kaunas, 2001. 792 p.

2. Lietuvos ežeru sqrašas (su morfometriniais duomenimis), Kaunas: RVŪPI, 1964. 129 p.

3. GLIOŽAITIS, A. Lietuvos kariuomenès geodezijos topografijos ir kartografijos darbų, atliktu 1920-1940 metais, apžvalga. Karo archyvas, 1997, 1.19, p. 113-176.

4. Lietuvos Respublikos ežerų klasifikatorius. Valstybès žinios, 2003, Nr. 34-1442, p. 40.

5. Lietuvos TSR upiu ir ežeru vardynas. Vilnius: Valstybinè politinès ir mokslinès literatūros leidykla, 1963. 226 p.

6. VANAGAS, A. Lietuviu hidronimu etimologinis žodynas. Vilnius: Mokslas, 1981. $408 \mathrm{p}$

7. PUPKIS, A.; RAZMUKAITĖ, M. Vietovardžiu žodynas. Vilnius: Mokslo ir enciklopedijų leidybos institutas, 2002. $462 \mathrm{p}$.
8. GAIGALIS, K.; JABLONSKIS, J. Pietryčiu Lietuvos hidrografija (ežerai). Vilnius: Mokslas, 1976. $101 \mathrm{p}$.

9. GIRKUS, R.; LUKOŠEVIČIUS, V. Šiuolaikinès Lietuvos kartografijos problemos dèl oikonimų ir hidronimu neatitikimu norminamuosiuose ir oficialiuosiuose leidiniuose. Geodezija ir kartografija, 2004, t. 30, Nr. 4, p. 123-126.

Romualdas GIRKUS. Chief specialist for heritage. Institute of Aerogeodesy ( $\mathrm{Ph}+37037451$ 504).

A graduate of Kaunas Politechnic Institute (now Kaunas University of Technology, geodetic engineer, 1962. Publications: over 20 scientific articles. Participant of conferences in Latvia, Russia.

Research interests: history of geodesy and cartography.

Viktoras Lukoševičius. Doctor, Assoc Prof. Dept of Civil Engineering Technology, Panevėžys Institute, Kaunas University of Technology ( $\mathrm{Ph}+37045435819$, fax +37045516161 ).

A graduate of Kaunas Politechnic Institute (now Kaunas University of Technology), geodetic engineer, 1962. Doctor's degree at Institute of Surveying, Aerial Photography and Cartography, Moscow, 1966. Publications: 2 books, over 60 research articles; participant of conferences in USA, Brasil, Sweden, Norwey, Russia. Fellowship Winner, NATO and Italy National Science Competition, 1996. Member of Association for the Advancement of Baltic Studies.

Research interests: history of geodesy and cartography. 